J Proteome Res. 2016 August 05; 15(8): 2688-2696. doi:10.1021/acs.jproteome.6b00237.

\title{
Discovery of Manassantin A Protein Targets using Large-Scale Protein Folding and Stability Measurements
}

\author{
M. Ariel Geer Wallace ${ }^{1}$, Do-Yeon Kwon ${ }^{1}$, Douglas H. Weitzel ${ }^{2}$, Chen-Ting Lee ${ }^{2}$, Tesia N. \\ Stephenson ${ }^{1}$, Jen-Tsan Chi $^{3,4}$, Robert A. Mook ${ }^{5}$, Mark W. Dewhirst ${ }^{2}$, Jiyong Hong ${ }^{1}$, and \\ Michael C. Fitzgerald ${ }^{1, *}$ \\ ${ }^{1}$ Department of Chemistry, Duke University, Durham, North Carolina 27708-0346 \\ ${ }^{2}$ Department of Radiation Oncology, Duke University Medical Center, Durham, North Carolina \\ 27710
}

${ }^{3}$ Department of Molecular Genetics \& Microbiology, Duke University Medical Center, Durham, North Carolina 27708

${ }^{4}$ Center for Genomic and Computational Biology, Duke University Medical Center, Durham, North Carolina 27708

${ }^{5}$ Department of Medicine, Duke University Medical Center, Durham North Carolina 27710

\begin{abstract}
Manassantin A is a natural product that has been shown to have anticancer activity in cell-based assays, but has a largely unknown mode-of-action. Described here is the use of two different energetics-based approaches to identify protein targets of manassantin A. Using the Stability of Proteins from Rates of Oxidation technique with an isobaric mass tagging strategy (iTRAQSPROX) and the pulse proteolysis technique with a Stable Isotope Labeling with Amino acids in Cell culture strategy (SILAC-PP), over 1,000 proteins in a MDA-MB-231 cell lysate grown under hypoxic conditions were assayed for manassantin A interactions (both direct and indirect). A total of 28 protein hits were identified with manassantin A-induced thermodynamic stability changes. Two of the protein hits (filamin A and elongation factor 1a) were identified using both experimental approaches. The remaining 26 hit proteins were only assayed in either the iTRAQSPROX or the SILAC-PP experiment. The 28 potential protein targets of manassantin A identified here provide new experimental avenues along which to explore the molecular basis of manassantin A's mode of action. The current work also represents the first application iTRAQ-SPROX and SILAC-PP to the large-scale analysis of protein-ligand binding interactions involving a potential anti-cancer drug with an unknown mode-of-action.
\end{abstract}

\section{TOC image}

\footnotetext{
*Address reprint requests to: Professor Michael C. Fitzgerald, Department of Chemistry, Box 90346, Duke University, Durham, North Carolina 27708-0346, Tel: 919-660-1547, Fax: 919-660-1605, michael.c.fitzgerald@ duke.edu.

Supporting Information Available: This material is available free of charge via the Internet at http://pubs.acs.org. The supporting information includes:
} 


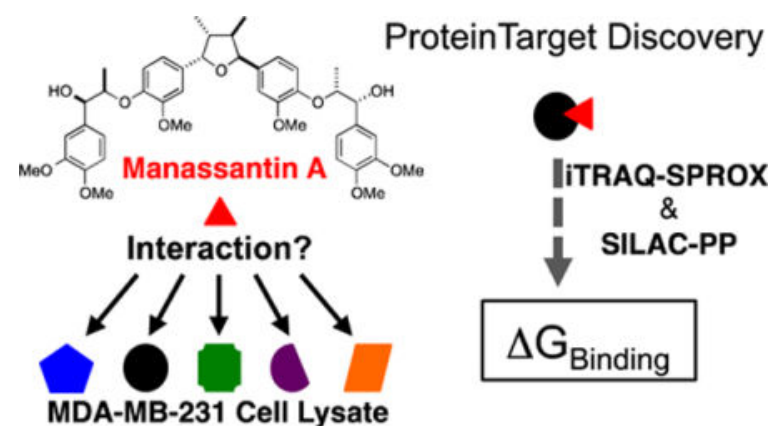

\section{Keywords}

Mass Spectrometry; SILAC; iTRAQ; Proteomics; Chemical Denaturation; MDA-MB-231; SPROX; Pulse Proteolysis; Mode-of-Action; Cancer; Manassantin A; Filamin A; Elongation Factor 1a

\section{INTRODUCTION}

Manassantin A is a natural product that has been isolated from the perennial herb Saururus chinensis Baill ${ }^{1}$ and the aquatic plant Saururus cernuus ${ }^{2-4}$ Manassantin A has been shown to have a variety of biological activities related to the treatment of a wide range of ailments including edema, jaundice, gonorrhea, and hepatoma in traditional medicine. ${ }^{1}$ In cell-based assays manassantin A has been shown to possess therapeutic potential for the treatment of diseases involving melanin production, ${ }^{5,6}$ atherosclerosis, ${ }^{7-9}$ and cancer. ${ }^{1,10-12}$ Manassantin A exhibits cytotoxicity against a wide range of cancer cell lines including HT-29, HepG2, PC-3, and MDA-MB-231, but weak cytotoxicity against non-cancer cell lines. ${ }^{1,10,11}$ This cytotoxic specificity makes manassantin A an attractive anti-cancer drug candidate.

The observed anti-cancer activity of manassantin A has been linked to its ability to inhibit hypoxia inducible factor $1 \mathrm{a}$ (HIF-1a). ${ }^{2,4,13} \mathrm{HIF}-1 \mathrm{a}$ is overexpressed in tumor cells under hypoxic conditions, where it binds to HIF-1 $\beta$ in the nucleus to form the transcription factor HIF-1 ${ }^{14,15}$ HIF-1 activation leads to expression of downstream target genes that promote tumor growth, angiogenesis, and metastasis. ${ }^{13,16} \mathrm{HIF}-1 \mathrm{a}$ inhibition by nanomolar concentrations of manassantin A has been observed in mouse mammary carcinoma 4T1 cells, in human breast MDA-MB-231 cells, ${ }^{17}$ and in human breast T47D cells ${ }^{18}$ with varying HIF-1a activities. ${ }^{19}$ Several manassantin A derivatives also inhibit HIF-1a in cellbased assays, some with lower $\mathrm{IC}_{50}$ values than the parent compound. ${ }^{12,16-18}$ One prominent HIF-1a target angiogenic gene, vascular endothelial growth factor (VEGF), is also inhibited by manassantin A. ${ }^{12,17,18}$ While many cell-based studies have shown inhibition of HIF-1a by manassantin A, the molecular mechanism(s) by which this inhibition occurs are unknown.

To identify the protein targets of manassantin A in hypoxic cells, we utilize two different energetics-based approaches to analyze a lysate of MDA-MB-231 cells grown under hypoxia. One approach is the Stability of Proteins from Rates of Oxidation technique ${ }^{20}$ with an isobaric mass tagging strategy (iTRAQ-SPROX). The second approach is the pulse 
proteolysis technique ${ }^{22}$ with a Stable Isotope Labeling with Amino acids in Cell culture strategy (SILAC-PP). ${ }^{23}$ The utility of iTRAQ-SPROX and SILAC-PP in protein target identification studies has been previously demonstrated with the proteins in yeast cell lysates with several drugs and enzyme co-factors with well-known protein targets. ${ }^{21,23-25}$ The current work represents the first application of iTRAQ-SPROX and SILAC-PP to identify the protein targets of a natural product with a largely unknown mode-of-action.

The iTRAQ-SPROX and SILAC-PP approaches are fundamentally similar. Both approaches rely on the chemical denaturant dependence of a protein modification reaction to report on the differential folding stability of proteins in the presence and in the absence of test ligands. However, the two approaches are operationally different as they utilize different modification reactions (i.e., methionine oxidation in SPROX and a proteolytic cleavage in PP) and different quantitative proteomics readouts (i.e., gel-based SILAC quantitation in PP and solution-based iTRAQ quantitation in SPROX) that rely on the detection and quantitation of different peptide probes. These operational differences make it attractive to use the two approaches simultaneously to cross-validate results obtained from the other. We have recently shown that such cross validation of iTRAQ-SPROX data with SILAC-PP data can be useful for differentiating false-positives from true-positives in protein target identification studies in which these approaches are employed. ${ }^{23}$

As part of this work, iTRAQ-SPROX was initially utilized to identify the proteins in a MDA-MB-231 cell lysate that may interact, either directly or indirectly, with manassantin A. The SILAC-PP technique was subsequently used to cross-validate the protein hits detected with manassantin A induced thermodynamic stability changes in the ITRAQ-SPROX experiment. Ultimately, the iTRAQ-SPROX and SILAC-PP experiments described here identified 21 and 9 protein hits, respectively. Two proteins, filamin A and elongation factor 1a, were identified that displayed hit behavior (i.e., manassantin A induced stability changes) in both the iTRAQ-SPROX and SILAC-PP experiments. Filamin A is a particularly intriguing protein hit, given its recently established role in the hypoxia-induced activation of HIF-1a. ${ }^{26}$

\section{MATERIALS and METHODS}

\section{ITRAQ-SPROX Protocol}

The iTRAQ-SPROX experiments were performed as previously described ${ }^{27}$ For each experiment, a MDA-MB-231 cell lysate (see Supporting Information) containing $\sim 5 \mu \mathrm{g} / \mu \mathrm{L}$ total protein was aliquoted into two $207 \mu \mathrm{L}$ portions. A $23 \mu \mathrm{L}$ aliquot of a $3 \mathrm{mM}$ manassantin A sample prepared in DMSO was added to one portion of the cell lysate to create the (+) ligand sample, and $23 \mu \mathrm{L}$ of DMSO was added to the other portion of the cell lysate to create the (-) ligand sample. The manassantin A was prepared by total chemical synthesis as described elsewhere The (+) and (-) ligand samples were equilibrated for $1.5 \mathrm{hr}$ at RT before $25 \mu \mathrm{L}$ aliquots of the (-) or (+) ligand samples were diluted into $20 \mu \mathrm{L}$ of GdmCl-containing buffers prepared in $20 \mathrm{mM}$ phosphate buffer, $\mathrm{pH}$ 7.4. The final [ $\mathrm{GdmCl}]$ in each buffer was $0.5,1.0,1.3,1.5,1.7,2.0,2.5$, and $3.0 \mathrm{M}$ and the final [manassantin A] was $120 \mu \mathrm{M}$. The protein samples in the $\mathrm{GdmCl}$-containing buffers were equilibrated for 1.5 $\mathrm{hr}$ at RT before the methionine oxidation reaction in SPROX was initiated with the addition 
of $5 \mu \mathrm{L}$ of $9.8 \mathrm{M} \mathrm{H}_{2} \mathrm{O}_{2}$. The oxidation reactions were quenched with $1 \mathrm{~mL}$ of $300 \mathrm{mM}$ methionine after $3 \mathrm{~min}$.

The proteins in each $\mathrm{GdmCl}$-containing buffer were precipitated upon addition of $250 \mu \mathrm{L}$ of $100 \%$ TCA (wt/vol) and overnight incubation on ice. The samples were centrifuged at 8,000 rcf for $30 \mathrm{~min}$ at $4^{\circ} \mathrm{C}$, and the supernatant was decanted. The protein pellets were washed four times with $300 \mu \mathrm{L}$ of ice-cold ethanol, and allowed to dry in a fume hood. The protein pellets were dissolved in $35 \mu \mathrm{L}$ of $0.5 \mathrm{M}$ TEAB with $0.1 \%$ final concentration of SDS. The samples were vortexed, heated at $60{ }^{\circ} \mathrm{C}$, and sonicated for $10 \mathrm{~min}$ at a time, for 2-3 cycles. The disulfide bonds were reduced with a final concentration of $5 \mathrm{mM}$ TCEP for $1 \mathrm{hr}$ at $60{ }^{\circ} \mathrm{C}$. The free cysteine residues were alkylated with a final concentration of $10 \mathrm{mM}$ MMTS for $10 \mathrm{~min}$ at RT. The proteins were digested with $1.0 \mu \mathrm{L}$ of $1 \mathrm{mg} / \mathrm{mL}$ trypsin at $37^{\circ} \mathrm{C}$ for $16 \mathrm{hr}$.

The $0.5,1.0,1.3,1.5,1.7,2.0,2.5$, and 3.0 M (-) and (+) manassantin A samples were labeled with the $113,114,115,116,117,118,119$, and 121 tags, respectively, according to the manufacturer's protocol with the exception that 0.5 (instead of 1.0) units of each tag was used in the labeling reaction. After the labeling reaction, $10 \mu \mathrm{L}$ of each sample was combined within a set, (-) or (+), and desalted using a C18 resin to create the non-enriched samples. Separately, $30 \mu \mathrm{L}$ portions of each sample within a set, $(-)$ or $(+)$, were also combined and the volume reduced to $\sim 50 \mu \mathrm{L}$ using a Speed Vac concentrator. The ( - ) and $(+)$ combined samples were subjected to a methionine enrichment procedure using a commercially available $\mathrm{Pi}^{3}{ }^{\mathrm{TM}}$ - Methionine Reagent kit according to the manufacturer's protocol.

\section{SILAC-Pulse Proteolysis Protocol}

Heavy and light labeled MDA-MB-231 cell lysates (see Supporting Information) containing $4.6 \mu \mathrm{g} / \mathrm{ML}$ of total protein were used to prepare the $(-)$ and $(+)$ manassantin A samples, respectively. The (-) sample contained $405 \mu \mathrm{L}$ of the heavy lysate and $45 \mu \mathrm{L}$ of DMSO. The (+) sample contained $405 \mu \mathrm{L}$ of the light lysate and $45 \mu \mathrm{L}$ of a $3 \mathrm{mM}$ manassantin A stock solution prepared in DMSO. The (-) and (+) samples were equilibrated at RT for $1 \mathrm{hr}$. A 25 $\mu \mathrm{L}$ aliquot of each equilibrated lysate, $(-)$ or $(+)$ manassantin $\mathrm{A}$, was transferred into $75 \mu \mathrm{L}$ of urea buffers in $20 \mathrm{mM}$ Tris- $\mathrm{HCl}, \mathrm{pH}$ 7.4. The final [urea] in each urea-containing buffer was $0,1.0,1.5,2.0,2.4,3.0,3.4,4.0,4.5,4.9,5.4,5.6$, and $6.2 \mathrm{M}$. The samples were incubated in the urea buffers for $1 \mathrm{hr}$ at RT.

The pulse proteolysis reaction in each urea buffer was initiated with the addition of $2.0 \mu \mathrm{L}$ of a $10 \mathrm{mg} / \mathrm{mL}$ thermolysin solution prepared in $2.5 \mathrm{M} \mathrm{NaCI}$ and $10 \mathrm{mM} \mathrm{CaCl} 2$. After $1 \mathrm{~min}$ the proteolysis reactions were quenched with $2.08 \mu \mathrm{L}$ of $0.5 \mathrm{M}$ EDTA. A total of $25 \mu \mathrm{L}$ of the (+) manassantin A (light) samples were combined with $25 \mu \mathrm{L}$ of the (-) control (heavy) samples from the same final [urea] in each experiment. The samples were fractionated by SDS-PAGE, and gelbands, corresponding to different protein molecular weight regions (see Figure S-1 in the Supporting Information), were excised. The protein material in each gelband was prepared for LC-MS/MS analysis as described elsewhere ${ }^{29}$ (see also additional details in Supporting Information).

J Proteome Res. Author manuscript; available in PMC 2017 August 05. 


\section{LC-MS/MS Analyses}

iTRAQ-SPROX-The iTRAQ-SPROX samples were analyzed on an Orbitrap Elite ETD mass spectrometer equipped with an Easy-nLC 1000 system. The trapping column was a $100 \mu \mathrm{m} \times 2 \mathrm{~cm}$ Integrafrit column (New Objective) packed with 200 A Magic C18 AQ $5 \mu \mathrm{m}$ material (Michrom). The column was a $75 \mu \mathrm{m} \times 25 \mathrm{~cm}$ PicoFrit column (New Objective) packed with $100 \AA$ A Magic C18 AQ $5 \mu \mathrm{m}$ material (Michrom). The flow rate was set to 400 $\mathrm{nl} / \mathrm{min}$. Solvent A consisted of $0.1 \%$ formic acid in $\mathrm{H}_{2} \mathrm{O}$ and solvent $\mathrm{B}$ was $0.1 \%$ formic acid in acetonitrile. The LC gradient increased from 5 to $7 \% \mathrm{~B}$ over $2 \mathrm{~min}, 7$ to $35 \% \mathrm{~B}$ over $90 \mathrm{~min}, 35$ to $50 \% \mathrm{~B}$ over $1 \mathrm{~min}$, was isocratic at $50 \% \mathrm{~B}$ for $9 \mathrm{~min}$, increased from 50 to $95 \%$ B over $1 \mathrm{~min}$, and finally isocratic at $95 \%$ B for 8 min. Product ion scans (resolution $15,000)$ were collected for the 10 most intense peaks in a given precursor scan (resolution 60,000 ) with an intensity threshold of 5,000. The dynamic exclusion window of a given $\mathrm{m} / \mathrm{z}$ ratio was set at $1 \mathrm{scan}$ in $0.75 \mathrm{~min}$ and the precursor isolation width was $1.2 \mathrm{~m} / \mathrm{z}$. The scan range for the precursor scan was $400-1,800 \mathrm{~m} / \mathrm{z}$ and $100-2,000 \mathrm{~m} / \mathrm{z}$ for the product ion scan. Collision induced dissociation was achieved using HCD with a normalized collision energy of $40 \%$ and an HCD activation time of $0.1 \mathrm{~ms}$. The mass spectrometry data from the iTRAQ-SPROX experiment have been deposited to the ProteomeXchange Consortium (http://proteomcentral.proteomeexchange.org) via the PRIDE partner repository ${ }^{30}$ with the dataset identifier to be released at the time of publication.

SILAC-PP-The SILAC-PP samples were analyzed on a Agilent 6520 Q-TOF mass spectrometer equipped with a Chip Cube interface (Agilent Technologies, Inc). Solvent A consisted of $\mathrm{H}_{2} \mathrm{O}$ with $0.1 \%$ formic acid and Solvent B consisted of acetonitrile with $0.1 \%$ formic acid. The solvent gradient increased linearly from 3 to $5 \% \mathrm{~B}$ over 2 min, 5 to $15 \% \mathrm{~B}$ over $2 \mathrm{~min}, 15$ to $60 \% \mathrm{~B}$ over $18 \mathrm{~min}, 60$ to $90 \%$ B over $3 \mathrm{~min}, 90$ to $100 \% \mathrm{~B}$ over $0.1 \mathrm{~min}$, 100 to $5 \% \mathrm{~B}$ over $1.9 \mathrm{~min}$, and then isocratic at $5 \% \mathrm{~B}$ for $3 \mathrm{~min}$. The flow rate was 0.4 $\mu \mathrm{L} / \mathrm{min}$ and the inclusion window for precursor ions was $4 \mathrm{~m} / \mathrm{z}$. An HPLC chip with a $40 \mathrm{~nL}$ trapping column and $75 \mu \mathrm{m} \times 43 \mathrm{~mm}$ column with $300 \AA$ Zorbax C18 packing $(5 \mu \mathrm{M})$ was employed. The collision induced dissociation energy was achieved using the equation 3.50 $\mathrm{V} / 100 \mathrm{~m} / \mathrm{z}$ with an off-set of $-4.80 \mathrm{~V}$. The drying gas was set to $6 \mathrm{~L} / \mathrm{min}$ at $350{ }^{\circ} \mathrm{C}$, the capillary voltage ranged from 1800-1850, the skimmer was set to $65 \mathrm{~V}$, and the fragmentor was set to $175 \mathrm{~V}$. Four precursor ions were selected for fragmentation in each cycle. The mass spectrometry data from the SILAC-PP experiment have been deposited to the ProteomeXchange Consortium (http://proteomcentral.proteomeexchange.org) via the PRIDE partner repository ${ }^{30}$ with the dataset identifier to be released at the time of publication.

\section{Proteomic Data Analysis}

ITRAQ-SPROX-Peak lists were extracted from the raw LC-MS/MS data files and the data were searched against the IPI_HUMAN_v_3_75.fasta.fasta database using Proteome Discoverer version 1.3.0.339. The enzyme was set as Trypsin, and up to 2 missed cleavages were a. The following modifications were used: fixed modifications of MMTS on cysteine, fixed modification of iTRAQ ${ }^{\circledR}$ 8-Plex on N-terminus and lysine residues, and variable modification of oxidation on methionine residues. The mass tolerances for precursor and fragment ions were set to $10 \mathrm{ppm}$ and $0.8 \mathrm{Da}$, respectively. Only peptides with high quality quantitative data (i.e., iTRAQ ${ }^{\circledR}$ reporter ion intensities at $\mathrm{m} / \mathrm{z} 113-121$ that summed to 
$>1,000$ ), with isolation purity of $70 \%$ or greater, and with false discovery rates (FDR) $<5 \%$, were used in subsequent analyses.

The iTRAQ-SPROX data analysis was performed as previously described ${ }^{27}$ Briefly, ITRAQ ${ }^{\circledR}$ reporter ion intensities were normalized (see Supporting Information) and used to generate chemical denaturation data sets for methionine-containing peptides from the (-) and (+) manassantin A SPROX experiments. Hit peptides were identified as those with significant transition midpoint shifts in the (-) and (+) manassantin A samples. Transition midpoints were assigned using a set of criteria (see Supporting Information) that we have previously established for the analysis of SPROX data. ${ }^{24,27}$ Significant transition midpoint shifts were taken to be those resulting from iTRAQ reporter ion differences in the (-) and (+) manassantin A samples at two or more iTRAQ tags, where at least one difference was between the transition regions of the two chemical denaturation curves obtained with and without ligand. Significant iTRAQ reporter ion differences were taken to be $>0.20$ or $<-0.18$ in Experiment 1 or $>0.14$ or $<-0.17$ in Experiment 2. These values were determined based on a global analysis of the data in each experiment, where the values represented the $90^{\text {th }}$ and $10^{\text {th }}$ percentiles of the iTRAQ reporter ion difference distribution (see Figure S-2). This requirement for hits to have two consecutive iTRAQ reporter ion differences less than the $10^{\text {th }}$ percentile or greater than the $90^{\text {th }}$ percentile produced hit peptides with an estimated $\mathrm{p}$ value $\$$.01. More detailed information about the iTRAQ-SPROX data analysis as well as Information about how $\mathrm{K}_{\mathrm{d}}$ values were determined from $\mathrm{C} 1 / 2$ value shifts can be found in the Supporting Information.

SILAC-PP-Peak lists were extracted from the raw LC-MS/MS data files and the data were searched on against the SwissProt Homo sapiens database using Spectrum Mill Workbench Software A.03.03. The enzyme was set as trypsin, and up to 3 missed cleavages were permitted. Fixed modifications for SILAC labeling at lysine ( 0 and $8 \mathrm{Da})$ and arginine $(0$ and $10 \mathrm{Da}$ ) and carbamidomethylation on cysteine residues were set along with variable modifications of methionine residue oxidation (0-1) and deamidation of asparagine residues. The mass tolerances for precursor and fragment ions were set to 20 and $50 \mathrm{ppm}$, respectively. Excel spreadsheets containing the peptide and protein identifications generated in this work are included in the Supporting Information (see Tables S-1-S-3).

The SILAC-PP search results were analyzed as previously reported. ${ }^{23}$ Briefly, the L/H ratios generated for all the peptides in identified in the experiment were used to determine a median $\mathrm{L} / \mathrm{H}$ ratio of 1.2 (see Figure $\mathrm{S} 3$ ). The $\mathrm{L} / \mathrm{H}$ ratios for all identified peptides from a particular protein were averaged for all identifications within a gel-band for a particular denaturant concentration, and these average $\mathrm{L} / \mathrm{H}$ ratios were used to generate SILAC-PP data sets. Peptides identified in four or more urea concentrations were considered for changes in thermodynamic stability upon ligand binding. Proteins with $>1.7$ fold deviations from the median $\mathrm{L} / \mathrm{H}$ ratio at two or more consecutive denaturant concentrations were labeled as hits. A global analysis of the $\mathrm{L} / \mathrm{H}$ ratios obtained revealed that $\sim 90 \%$ of the ratios were within 1.7-fold of the median value (see Figure S-3 in the Supporting Information). The 5.25 M sample labeled " $\mathrm{H}$ " contained a relatively large number of high $\mathrm{L} / \mathrm{H}$ ratios $(\mathrm{L} / \mathrm{H}$ ratios \ 1.2) compared to the rest of the denaturant concentrations. The data for this sample were not included in the SILAC-PP data analysis. 


\section{RESULTS \\ ITRAQ-SPROX Analyses}

Two replicate iTRAQ-SPROX experiments were performed using the experimental workflow outlined in Figure 1 to assay the proteins in an MDA-MB-231 cell lysate for manassantin A-induced thermodynamic stability changes. The MDA-MB-231 cell lysates used in the each of the iTRAQ-SPROX experiments were derived from MDA-MB-231 cells exposed to hypoxic conditions in order to identify interacting proteins under hypoxia. The proteomic coverages obtained in the two iTRAQ-SPROX experiments are summarized in Table 1. Between the two experiments, over 1100 proteins were assayed for thermodynamic stability changes induced by manassantin A using more than 2,300 peptide probes.

Shown in Figure 2A is an iTRAQ-SPROX data set generated for a representative non-hit methionine-containing peptide probe from Hsp90, which did not show a stability change in the presence of manassantin A. iTRAQ-SPROX data sets for hit peptides from filamin A and elongation factor $1 \mathrm{a}$ are also shown in Figure $2 \mathrm{~B}$ and $2 \mathrm{C}$, respectively. The peptide from filamin A showed a decrease in thermodynamic stability in the presence of manassantin A, while the peptide from elongation $1 \mathrm{a}$ showed an increase in stability. If the measured $\Delta \mathrm{C}_{1 / 2}$ value of $+0.6 \mathrm{M}$ for elongation factor $1 \mathrm{a}$ is assumed to result from a direct binding interaction between elongation factor $1 a$ and manassantin $A$ then the $K_{d}$ value for this interaction can be estimated at $8.8 \mu \mathrm{M}$.

The number of peptide and protein hits identified in each iTRAQ-SPROX experiment are summarized in Table 1. The fraction of hit peptides observed in each iTRAQ-SPROX experiment, $\sim 1.2$ and $0.8 \%$, is very close to the falsepositive rate for iTRAQ-SPROX experiments, which has been previously established to be on the order of $\sim 1 \% .{ }^{31}$ Indeed, 12 of the 32 hit peptides identified in iTRAQ-SPROX Experiments 1 and 2 did not display consistent hit behavior across the two biological replicates (e.g., the peptide probe was a hit in one experiment and not the other) (see Table S-4). Ultimately, these 12 peptides that showed inconsistent hit behavior in the two iTRAQ-SPROX experiments were deemed falsepositives and removed from the final iTRAQ-SPROX hit list summarized in Table 2. The one peptide hit from the T-complex protein 1 subunit $a$, which meet all the hit selection criteria in Experiment 1 (i.e., displayed a significant $C_{1 / 2}$ value shift), did show a small shift in Experiment 2. Thus, this protein is also included in Table 2.

\section{SILAC-PP Analysis}

The experimental workflow used in the SILAC-PP experiment is shown in Figure 3. The SILAC-PP experiment involved preparation of both light and heavy labeled MDA-MB-231 cells each exposed to hypoxic conditions prior to preparation of the cell lysates. The SILACPP experiment requires an SDS-PAGE fractionation step prior to LC-MS/MS analysis. The two SDS-PAGE gels and the approximate molecular weight regions of the gel bands that were generated in the SILAC-PP experiment are shown in Figure S-1. Listed in Table S-5 are the numbers of peptides and proteins assayed in each molecular weight region of the gels. In total, 263 unique peptides from 99 proteins were assayed in the SILAC-PP 
experiment (Tables S-5 and S-6). The 9 protein hits identified in the SILAC-PP experiment are summarized in Table 3.

Included in the 99 proteins assayed in the SILAC-PP experiment were 6 of the 21 protein hits identified in the iTRAQ-SPROX experiments. Two of these 6 iTRAQ-SPROX protein hits, filamin A and elongation factor 1a, were also identified as hits in the SILAC-PP experiment (see Figure 4). Moreover, the SILAC-PP data collected on filamin A and elongation factor $1 a$ were consistent with the observed destabilization of filamin $A$ and the stabilization of elongation factor 1a in iTRAQ-SPROX. SILAC-PP data collected on the other 4 iTRAQ-SRPOX protein hits assayed in the SILAC-PP experiment (pyruvate kinase, stress-70 protein, phophoglycerate kinase 1 , and heat shock protein $90 \mathrm{kDa} \beta$ ) did not have the altered $\mathrm{L} / \mathrm{H}$ ratios expected for a hit protein in the SILAC-PP experiment. Two of the 9 protein hits identified in the SILAC-PP experiment (heat shock cognate $71 \mathrm{kDa}$ protein and filamin B), were assayed with methionine-containing peptide probes in the iTRAQ-SPROX experiment, but the methionine-containing peptide probes assayed did not show hit behavior.

\section{DISCUSSION}

\section{Proteomic Coverage}

This study is the first large-scale, unbiased analysis of protein-binding interactions with manassantin A. The iTRAQ-SPROX experiment enabled over 1,100 different proteins to be assayed for manassantin A binding using over 2,300 methionine-containing peptide probes (Table S-4). The peptide probes in iTRAQ-SPROX need not be directly located in the manassantin A binding site of a protein in order to be a useful probe of ligand-induced protein folding stability changes in iTRAQ-SPROX. In theory, one methionine-containing peptide probe can report on the protein folding thermodynamics of the entire protein folding domain to which it maps. Many proteins assayed in the iTRAQ-SPROX experiments reported here were represented by multiple methionine-containing peptide probes from different structural domains. This allowed multiple domains of many proteins to be included in the screen.

A number of the hit proteins identified in the iTRAQ-SPROX experiment were assayed with peptide probes in addition to the hit peptide which did not show stability changes in the presence of manassantin A (see Table S-4). For example, the filamin A protein was assayed with a total of 13 methionine-containing peptide probes, respectively. These peptides mapped to different domains of this large cytoskeletal protein (see Figure 5). However, only one methionine containing peptide probe from domain 6 of filamin A displayed hit behavior, suggesting that only this domain has an altered protein folding stability in the presence of manassantin A.

Ligand-induced stability changes in hit proteins detected in the iTRAQ-SPROX and SILACPP experiments can result from a variety of different phenomena. For example, a direct binding event between manassantin A and a hit protein can stabilize the ligand binding domain. However, protein hits identified using these methods can also be the result of indirect effects of ligand binding. For example, direct binding of manassantin A to one region of a protein could induce conformational changes that are destabilizing in another 
region of the protein. Additionally, the direct binding of manassantin A to one protein could also induce conformational changes in other proteins through disruption of protein-protein interactions. Additional studies on the 28 manassantin A protein targets identified here are needed to uncover the biophysical phenomena responsible for the detected stabilizations/ destabilizations. For example, manassantin A binding experiments using purified samples of each hit protein can be used to determine if detected stabilizations result from direct binding interactions. Pull-down experiments in the presence and absence of ligand using the hit proteins as bait can also be used to better understand the network of protein-protein interactions involved in indirect binding interactions.

In contrast to iTRAQ-SPROX, hit peptides in SILAC-PP do not necessarily provide direct information on the protein domain(s) that are affected by ligand binding. This is result of the protein-level readout in SILAC-PP (i.e., the necessity to separate the intact protein from the cleavage products using SDS-PAGE). The protein level readout used in SILAC-PP also complicates the assignment of ligand induced stabilizations and destabilizations. The sign of $\Delta \mathrm{C}_{1 / 2}$ values generated in SILAC-PP can only be used to assign stabilization or destabilizations when gel bands corresponding exclusively to the intact protein are analyzed. This was the case for the filamin A and elongation 1a hits detected in rows 1 and 5 (respectively) of the gel in the SILAC-PP experiment (Table 3). As expected for true positives, the SILAC-PP hit behaviors of filamin A and elongation $1 \mathrm{a}$ in rows 1 and 5 (respectively), are consistent with the iTRAQ-SPROX results (i.e., in both experiments filamin A is destabilized and elongation factor $1 a$ is stabilized in the presence of manassantin A).

\section{Experimental Overlap between ITRAQ-SPROX and SILAC-PP}

One goal of this work was to corroborate hits obtained in the iTRAQ-SPROX experiment using SILAC-PP results. Both experimental approaches report on the same chemical denaturant-induced equilibrium unfolding properties of proteins and protein-ligand complexes. However, the two experimental approaches rely on the detection and quantitation of different peptide probes using different quantitative proteomics readouts. Thus, one technique can be used to validate results from the other. Two proteins, filamin A and elongation factor $1 a$, were identified as hits in both the iTRAQ-SPROX and SILAC-PP experiments described here. Detection of these two proteins as hits in both the iTRAQSPROX and SILAC-PP experiments suggests that these proteins are true positives.

The 99 proteins assayed in the SILAC-PP experiment included 4 additional protein hits identified in the iTRAQ-SPROX experiments. Two of these 4 protein hits (pyruvate kinase and phoshoglycerate kinase), were not hits in the SILAC-PP experiment. It is unclear if these two protein hits are false-positives in the iTRAQ-SPROX experiment or false-negatives in the SILAC-PP experiment. Unfortunately, the SILAC-PP data collected on the other two iTRAQ-SPROX hits (i.e., the stress-70 protein and heat shock protein $90 \mathrm{kDa} \beta$ ) did not include $\mathrm{L} / \mathrm{H}$ ratios at the specific denaturant concentrations expected to be involved in the transition midpoint shift. Thus, even though these latter two iTRAQ-SPROX protein hits were technically assayed in the SILAC-PP experiment, the SILAC-PP data could not be used conclusively validate or invalidate the iTRAQ-SPROX results on these two proteins. 
Two SILAC-PP hits, heat shock cognate $71 \mathrm{kDa}$ protein and filamin B, were assayed in iTRAQ-SPROX but did not display hit behavior. SILAC-PP hits that are assayed but not detected as hits in iTRAQ-SPROX are not necessarily false positives in the iTRAQ-SPROX experiment. This is because the peptide level readout in iTRAQ-SPROX requires detection of a methionine-containing peptide probe that maps to the specific protein folding domain in which the ligand-induced stability change occurs. Unfortunately, it is not always possible to detect and quantify methionine-containing probes from every domain of a protein in iTRAQSPROX. In contrast, the protein level readout in SILAC-PP enables any identifying peptide in the bottom-up proteomics readout to report on ligand-induced stability changes in the SILAC-PP experiment. The peptide probe need not map to the specific protein folding domain in which the ligand-induced stability change occurs. Thus, the heat shock cognate 71 $\mathrm{kDa}$ and filamin B proteins that were detected as hits in SILAC-PP and not in iTRAQSPROX are not necessarily false positives. Indeed, both of these proteins are large multidomain proteins and the non-hit methionine-containing peptide probes detected in the iTRAQ-SPROX experiment were only from selected domains (e.g, from either the N- or Cterminal 130 amino acids of the 646 amino acid heat shock cognate $71 \mathrm{kDa}$ protein).

\section{Filamin A}

Filamin A, which was consistently identified as a hit in both the iTRAQ-SPROX and SILAC-PP experiments, has recently been linked to HIF-1a signaling. ${ }^{26}$ A hypoxia-induced and calpain-dependent cleavage in the first hinge region of filamin A (see Figure 5) has been shown to generate a $\mathrm{C}$-terminal fragment of filamin $\mathrm{A}$ that that binds to the $\mathrm{N}$-terminus of HIF-1a. This binding interaction ultimately leads to the nuclear localization and transactivation of HIF-1a. Therefore, the observed interaction with filamin A suggests a potential functional role in the HIF-1a inhibition by manassantin. Interestingly, the methionine-containing peptide probe from filamin A that was detected as a hit in our experiments is from domain 6 , which is $\mathrm{N}$-terminal to the calpain cleavage site in filamin A (Figure 5). The observed manassantin A-induced destabilization also suggests that the domain 6 is not the site of a direct manassantin A binding interaction, but rather the site of a conformational change induced by manassantin A binding to another region of filamin A or to another filamin A interacting protein. Our results suggest that this manassantin A-induced conformational change in filamin A may be a part of the molecular mechanism by which manassantin A inhibits HIF-1a.

\section{CONCLUSION}

Over 1,000 unique human proteins in an MDA-MB-231 cell lysate were assayed for manassantin A interactions using the iTRAQ-SPROX and SILAC-PP techniques. A total of 28 potential protein targets of manassantin A were identified in these experiments. Most of these 28 potential protein targets were only assayed in either the iTRAQ-SPROX or SILACPP experiment. However, two proteins, filamin A and elongation factor 1a, were identified as protein hits in both the iTRAQ-SPROX and SILAC-PP experiments. Filamin A, is a particularly intriguing hit protein given its recently established role in the hypoxia-induced activation of HIF-1a's transcriptional activity. Filamin A and the other 28 proteins identified 
here with manassantin A-induced thermodynamic stability changes provide an important starting point for understanding manassantin A's mode of action.

\section{Supplementary Material}

Refer to Web version on PubMed Central for supplementary material.

\section{Acknowledgments}

This work was supported in part by a grant from the US National Science Foundation (CHE-1308093) to M.C.F., a grant form the US National Institutes of Health (2RO1GM-084174-06) to M.C.F., and a grant from the American Cancer Society (Grant 122057-RSG-12-045-01-CDD) to J.H. The authors also thank the Proteomics Facility at the Fred Hutchinson Cancer Research Center for collecting the LC-MS/MS data in the iTRAQ-SPROX experiments.

\section{References}

1. Song SY, Lee I, Park C, Lee H, Hahm JC, Kang WK. Neolignans from Saururus chinensis inhibit PC-3 prostate cancer cell growth via apoptosis and senescence-like mechanisms. Int J Mol Med. 2005; 16(4):517-23. [PubMed: 16142381]

2. Hossain CF, Kim YP, Baerson SR, Zhang L, Bruick RK, Mohammed KA, Agarwal AK, Nagle DG, Zhou YD. Saururus cernuus lignans - Potent small molecule inhibitors of hypoxia-inducible factor-1. Biochem Bioph Res Co. 2005; 333(3):1026-1033.

3. Rao KV, Alvarez FM. Manassantins a/B and Saucerneol - Novel Biologically-Active Lignoids from Saururus-Cernuus. Tetrahedron Lett. 1983; 24(45):4947-4950.

4. Hodges TW, Hossain CF, Kim YP, Zhou YD, Nagle DG. Molecular-targeted antitumor agents: The Saururus cernuus dineolignans manassantin B and 4-O-demethylmanassantin B are potent inhibitors of hypoxia-activated HIF-1. J Nat Prod. 2004; 67(5):767-771. [PubMed: 15165135]

5. Seo CS, Lee WH, Chung HW, Chang EJ, Lee SH, Jahng Y, Hwang BY, Son JK, Han SB, Kim Y. Manassantin A and B from Saururus chinensis inhibiting cellular melanin production. Phytother Res. 2009; 23(11):1531-6. [PubMed: 19367669]

6. Lee HD, Lee WH, Roh E, Seo CS, Son JK, Lee SH, Hwang BY, Jung SH, Han SB, Kim Y. Manassantin A inhibits cAMP-induced melanin production by down-regulating the gene expressions of MITF and tyrosinase in melanocytes. Exp Dermatol. 2011; 20(9):761-763. [PubMed: 21569106]

7. Rho MC, Kwon OE, Kim K, Lee SW, Chung MY, Kim YH, Hayashi M, Lee HS, Kim YK. Inhibitory effects of manassantin A and B isolated from the roots of Saururus chinensis on PMAinduced ICAM-1 expression. Planta Med. 2003; 69(12):1147-9. [PubMed: 14750033]

8. Kwon OE, Lee HS, Lee SW, Chung MY, Bae KH, Rho MC, Kim YK. Manassantin A and B isolated from Saururus chinensis inhibit TNF-alpha-induced cell adhesion molecule expression of human umbilical vein endothelial cells. Arch Pharm Res. 2005; 28(1):55-60. [PubMed: 15742809]

9. Lee WS, Lee DW, Baek YI, An S, Cho KH, Choi YK, Kim HC, Park HY, Bae KH, Jeong TS. Human ACAT-1 and -2 inhibitory activities of saucerneol B, manassantin A and B isolated from Saururus chinensis. Bioorg Med Chem Lett. 2004; 14(12):3109-12. [PubMed: 15149654]

10. Lee YK, Seo CS, Lee CS, Lee KS, Kang SJ, Jahng Y, Chang HW, Son JK. Inhibition of DNA topoisomerases I and II and cytotoxicity by lignans from Saururus chinensis. Arch Pharm Res. 2009; 32(10):1409-15. [PubMed: 19898804]

11. Hahm JC, Lee IK, Kang WK, Kim SU, Ahn YJ. Cytotoxicity of neolignans identified in Saururus chinensis towards human cancer cell lines. Planta Med. 2005; 71(5):464-9. [PubMed: 15931587]

12. Kwon DY, Lee HE, Weitzel DH, Park K, Lee SH, Lee CT, Stephenson TN, Park H, Fitzgerald MC, Chi JT, Mook RA, Dewhirst MW, Lee YM, Hong J. Synthesis and Biological Evaluation of Manassantin Analogues for Hypoxia-Inducible Factor 1 alpha Inhibition. J Med Chem. 2015; 58(19):7659-7671. [PubMed: 26394152] 
13. Barliya T, Mandel M, Livnat T, Weinberger D, Lavie G. Degradation of HIF-1alpha under hypoxia combined with induction of Hsp90 polyubiquitination in cancer cells by hypericin: a unique cancer therapy. PLoS One. 2011; 6(9):e22849. [PubMed: 21949677]

14. Semenza GL. Evaluation of HIF-1 inhibitors as anticancer agents. Drug Discov Today. 2007; 12(19-20):853-9. [PubMed: 17933687]

15. Krishnamachary B, Semenza GL. Analysis of hypoxia-inducible factor 1alpha expression and its effects on invasion and metastasis. Method Enzymol. 2007; 435:347-54.

16. Semenza GL. Regulation of mammalian O2 homeostasis by hypoxia-inducible factor 1 . Annu Rev Cell Dev Biol. 1999; 15:551-78. [PubMed: 10611972]

17. Kasper AC, Moon EJ, Hu X, Park Y, Wooten CM, Kim H, Yang W, Dewhirst MW, Hong J. Analysis of HIF-1 inhibition by manassantin A and analogues with modified tetrahydrofuran configurations. Bioorg Med Chem Lett. 2009; 19(14):3783-6. [PubMed: 19423348]

18. Hossain CF, Kim YP, Baerson SR, Zhang L, Bruick RK, Mohammed KA, Agarwal AK, Nagle DG, Zhou YD. Saururus cernuus lignans-potent small molecule inhibitors of hypoxia-inducible factor-1. Biochem Biophys Res Commun. 2005; 333(3):1026-33. [PubMed: 15967416]

19. Gatza ML, Kung HN, Blackwell KL, Dewhirst MW, Marks JR, Chi JT. Analysis of tumor environmental response and oncogenic pathway activation identifies distinct basal and luminal features in HER2-related breast tumor subtypes. Breast Cancer Res. 2011; 13(3):R62. [PubMed: 21672245]

20. West GM, Tang L, Fitzgerald MC. Thermodynamic analysis of protein stability and ligand binding using a chemical modification- and mass spectrometry-based strategy. Anal Chem. 2008; 80(11): 4175-85. [PubMed: 18457414]

21. Dearmond PD, Xu Y, Strickland EC, Daniels KG, Fitzgerald MC. Thermodynamic analysis of protein-ligand interactions in complex biological mixtures using a shotgun proteomics approach. $\mathrm{J}$ Proteome Res. 2011; 10(11):4948-58. [PubMed: 21905665]

22. Park C, Marqusee S. Pulse proteolysis: a simple method for quantitative determination of protein stability and ligand binding. Nat Methods. 2005; 2(3):207-12. [PubMed: 15782190]

23. Adhikari J, Fitzgerald MC. SILAC-pulse proteolysis: A mass spectrometry-based method for discovery and cross-validation in proteome-wide studies of ligand binding. J Am Soc Mass Spectrom. 2014; 25(12):2073-83. [PubMed: 25315461]

24. Geer MA, Fitzgerald MC. Characterization of the Saccharomyces cerevisiae ATP-Interactome using the iTRAQ-SPROX Technique. J Am Soc Mass Spectrom. 2015

25. West GM, Tucker CL, Xu T, Park SK, Han X, Yates JR 3rd, Fitzgerald MC. Quantitative proteomics approach for identifying protein-drug interactions in complex mixtures using protein stability measurements. Proc Natl Acad Sci USA. 2010; 107(20):9078-82. [PubMed: 20439767]

26. Zheng X, Zhou AX, Rouhi P, Uramoto H, Boren J, Cao Y, Pereira T, Akyurek LM, Poellinger L. Hypoxia-induced and calpain-dependent cleavage of filamin A regulates the hypoxic response. Proc Natl Acad Sci USA. 2014; 111(7):2560-5. [PubMed: 24550283]

27. Strickland EC, Geer MA, Tran DT, Adhikari J, West GM, DeArmond PD, Xu Y, Fitzgerald MC. Thermodynamic analysis of proteinligand binding interactions in complex biological mixtures using the stability of proteins from rates of oxidation. Nat Protoc. 2013; 8(1):148-161. [PubMed: 23257983]

28. Kim H, Kasper AC, Moon EJ, Park Y, Wooten CM, Dewhirst MW, Hong J. Nucleophilic addition of organozinc reagents to 2-sulfonyl cyclic ethers: stereoselective synthesis of manassantins A and B. Org Lett. 2009; 11(1):89-92. [PubMed: 19111058]

29. Shevchenko A, Tomas H, Havlis J, Olsen JV, Mann M. In-gel digestion for mass spectrometric characterization of proteins and proteomes. Nat Protoc. 2006; 1(6):2856-60. [PubMed: 17406544]

30. Vizcaino JA, Cote RG, Csordas A, Dianes JA, Fabregat A, Foster JM, Griss J, Alpi E, Birim M, Contell J, O'Kelly G, Schoenegger A, Ovelleiro D, Perez-Riverol Y, Reisinger F, Rios D, Wang R, Hermjakob H. The PRoteomics IDEntifications (PRIDE) database and associated tools: status in 2013. Nucleic Acids Res. 2013; 41:D1063-9. (Database issue). [PubMed: 23203882]

31. Strickland EC, Geer MA, Hong J, Fitzgerald MC. False-Positive Rate Determination of Protein Target Discovery using a Covalent Modification- and Mass Spectrometry-Based Proteomics Platform. J Am Soc Mass Spectrom. 2013 


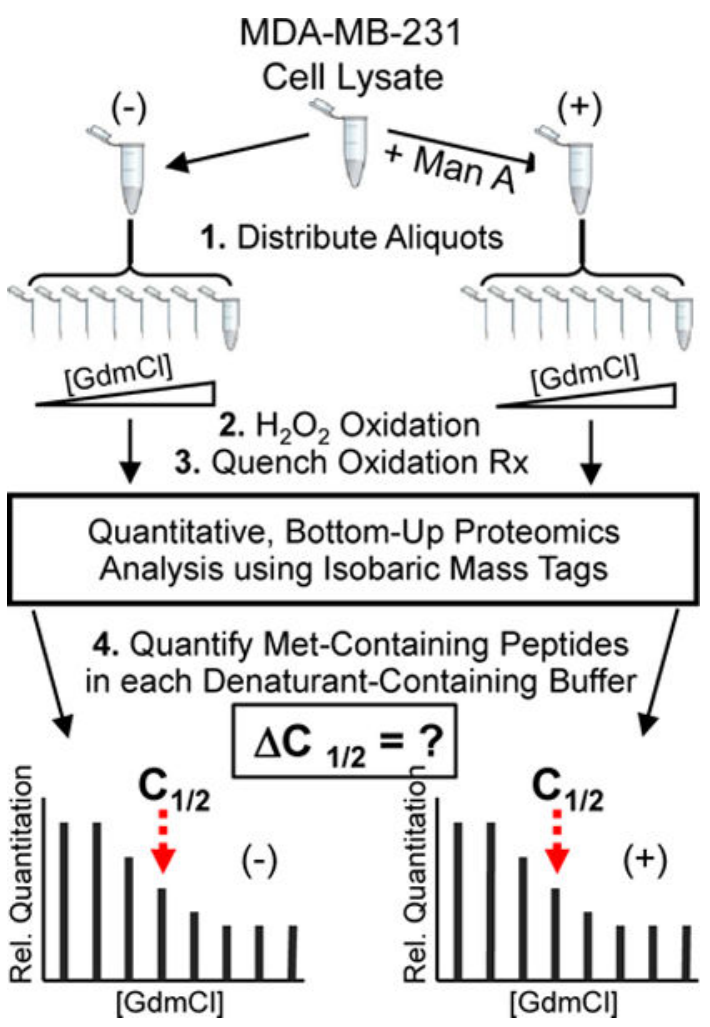

Figure 1.

Schematic representation of the iTRAQ-SPROX workflow utilized in this work. 

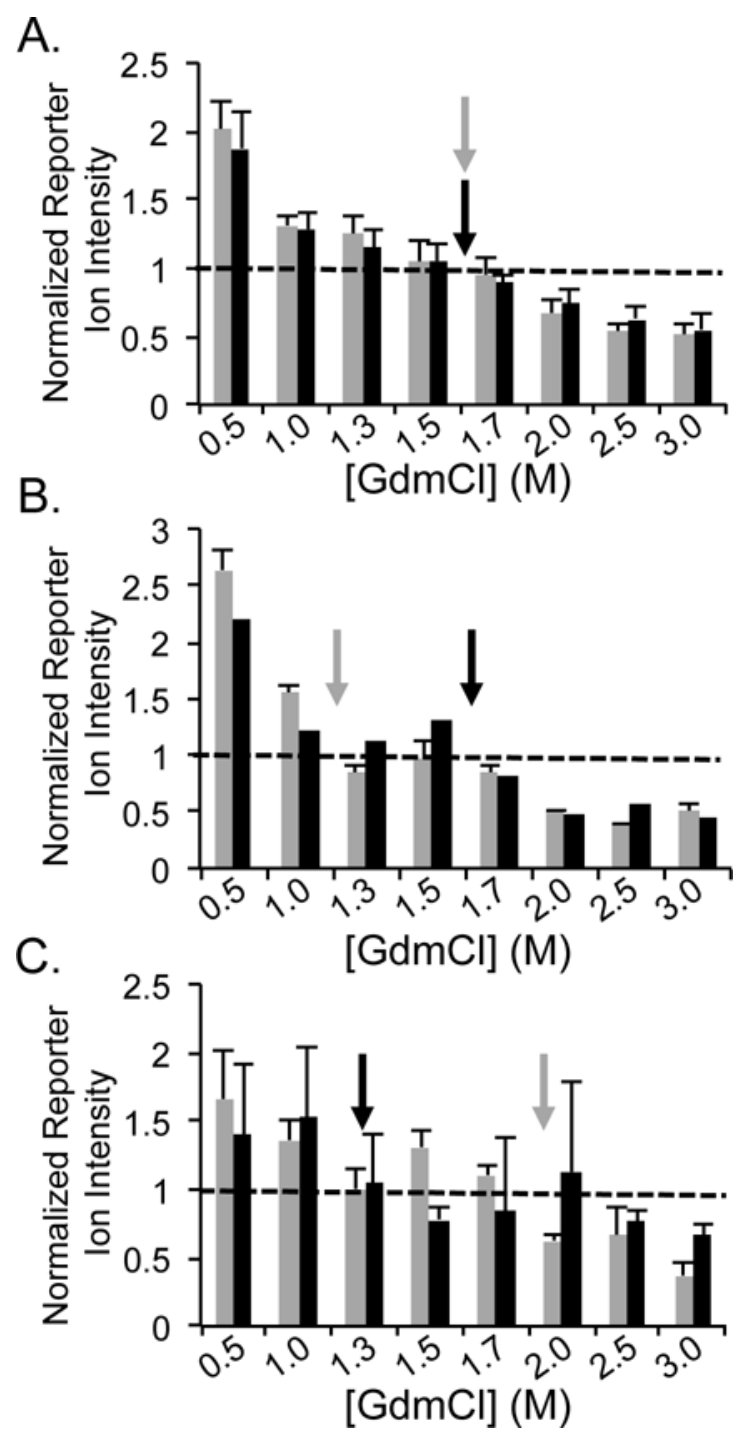

Figure 2.

Representative iTRAQ-SPROX data sets. Chemical denaturation data generated for a non-hit peptide TLTIVDTGIGMTK from Hsp90 assayed in Exp. 1 is shown in (A). The data for two peptide hits, MDSTEPPYSQK and GAGSYTIMVLFADQATPTSPIR, from elongation factor 1a and filamin A are shown in (B) and (C) (respectively). The light and dark shaded bars correspond to the (-) and (+) The $\mathrm{C}_{1 / 2}$ values are indicated with vertical arrows. The horizontal dashed lines indicate the normalized reporter ion intensity that was used as the cut-off value that separates the pre- and post-transition baselines. In cases where data from multiple product ion mass spectra was collected, the averaged data is reported along with error bars that represent one standard deviation. 


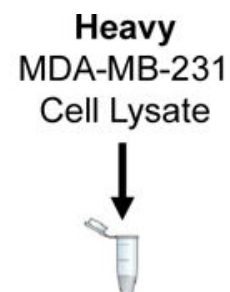

\section{Light}

MDA-MB-231

Cell Lysate

(-) 1. Distribute Aliquots $(+)$

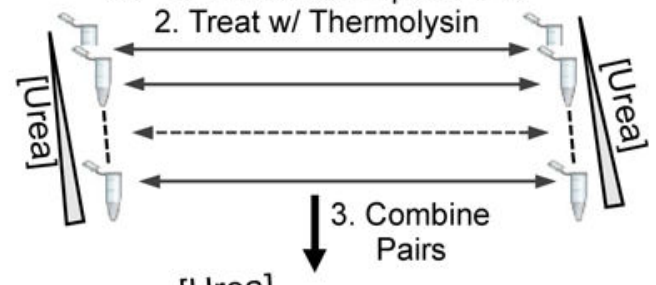

[Urea]

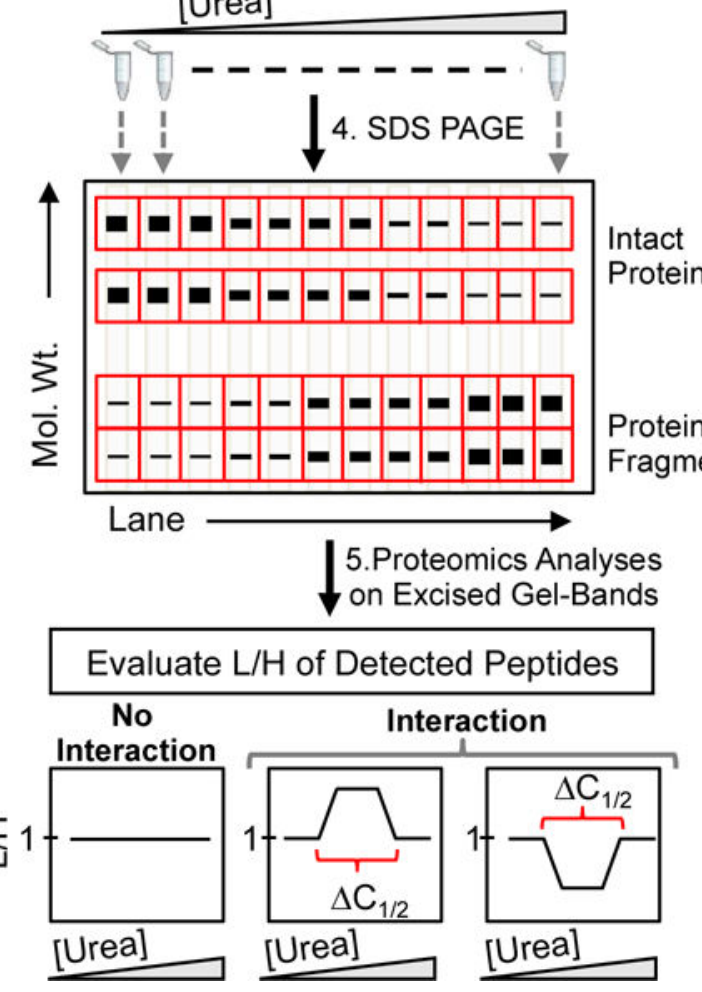

Figure 3.

Schematic representation of the SILAC-PP workflow utilized in this work. 

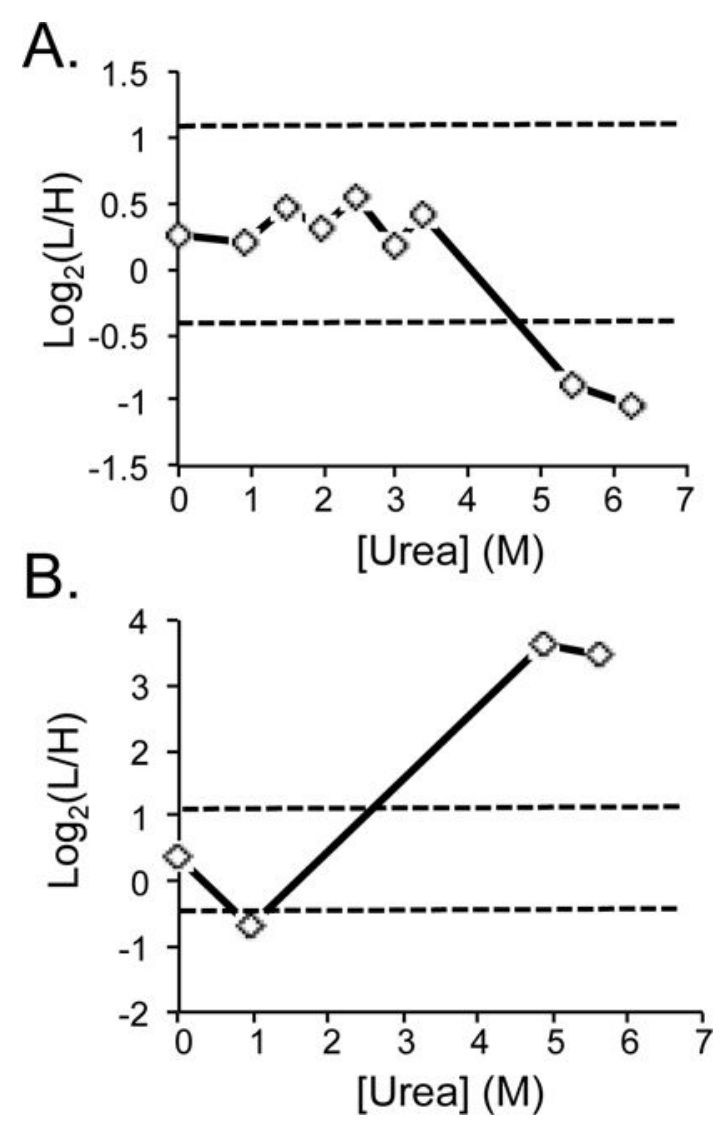

Figure 4.

SILAC-PP data generated on three iTRAQ-SPROX protein hits. (A) The average $\log _{2} \mathrm{~L} / \mathrm{H}$ ratios determined from 15 filamin A peptides in the analysis of the gel-bands excised from row 1 in the SDS-PAGE gel (i.e., the >150 kDa region of the gel). (B) The Log2 L/H ratios determined for the a peptide from elongation factor $1 a$ in the analysis of the gel bands excised from row 5 in the SDS-PAGE gel (i.e., the 55-65 kDa region of the gel). The horizontal dotted lines mark the regions within 1.7-fold of the median $\mathrm{L} / \mathrm{H}$ ratio of all the peptides identified in the SILAC-PP experiment 


\section{Filamin A}

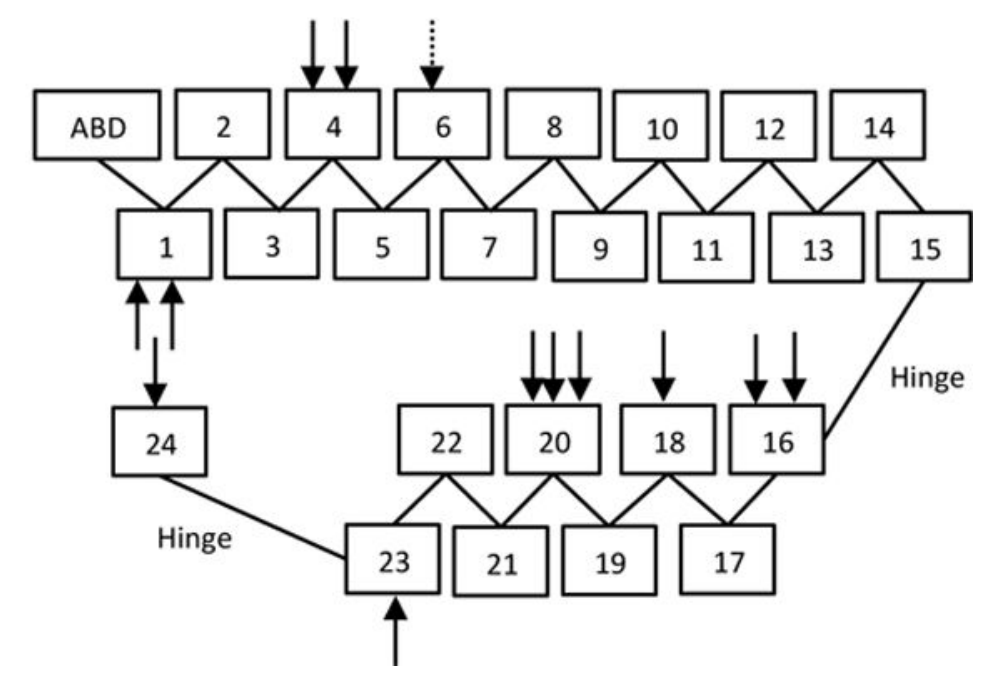

Figure 5.

Schematic representation of filamin A. The arrows indicate the location of the 13 methionine residues in the 13 methionine-containing peptide probes assayed in the iTRAQ-SPROX experiment described here. The dotted arrow indicates the location of the methionine in the hit peptide probe. 
Table 1

Summary of the proteomic coverages obtained in the iTRAQ-SPROX experiments.

\begin{tabular}{cccc}
\hline Experiment & Peptides Assayed $^{\boldsymbol{a}}$ & Proteins Assayed $^{\boldsymbol{b}}$ & Hit Peptides (Proteins) $^{\boldsymbol{c}}$ \\
\hline 1 & 1737 & 766 & $20(20)$ \\
2 & 1456 & 647 & $12(12)$ \\
Total & 2314 & 1143 & $32(32)$ \\
\hline
\end{tabular}

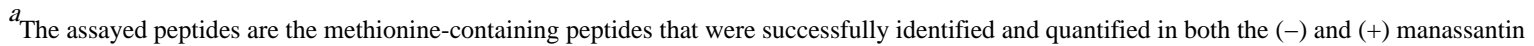
A samples.

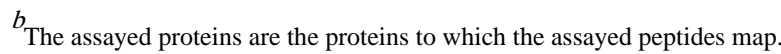

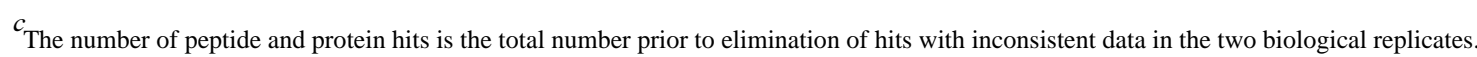




\section{Table 2}

Summary of peptide and protein hits with consistent data in the two replicate iTRAQ-SPROX experiments. Bolded protein entries were also identified as hits in SILAC-PP. These consistent hits were either identified as a hit in both experiments or only assayed in the one experiment in which they were a hit.

\begin{tabular}{|c|c|c|c|c|}
\hline Protein Name & Accession Number & Peptide Sequence & Exp. & $\Delta \mathrm{C}_{1 / 2}(\mathrm{M})^{a}$ \\
\hline Stress-70 protein & P38646 & ETGVDLTKDNMALQR & 1 & $-0.3^{b, c}$ \\
\hline Hexokinase-2 & P52789 & VDQYLYHMR & 1 & $-0.4^{b, c}$ \\
\hline Elongation factor $1 a$ & P68104 & MDSTEPPYSQK & 1 & $+\mathbf{0 . 4} 4^{b, d}$ \\
\hline Phosphoglycerate kinase 1 & $\mathrm{P} 00558$ & IVKDLMSK & 1 & $-0.3^{c}$ \\
\hline Pyruvate kinase & P14618 & SVETLKEMIK & 1 & $-0.3^{c}$ \\
\hline Ribosomal protein L14 & Q61PH7 & MTDFDRFK & 1 & $-0.4^{d}$ \\
\hline UDP-galactose 4-epimerase & Q5QPPI & SVEFEEMDILDQGALQR & 1 & $+0.6^{c}$ \\
\hline Ribosomal protein $\mathrm{S} 3$ & P23396 & FIMESGAK & 1 & $+1.0^{e}$ \\
\hline Heat Shock Protein $90 \mathrm{kDa} \beta$ & P14625 & EFEPLLNWMK & 1 & $+0.4^{c}$ \\
\hline Translation initiation factor 3 & Q7L2H7 & VMVELLGSYTEDNASQAR & 1 & $-0.6^{c}$ \\
\hline Acireductone Dioxygenase & Q9BV57 & GDMVTLPAGIYHR & 1 & $-0.4^{c}$ \\
\hline a-Actin-related protein 1 homolog $\mathrm{A}$ & P61193 & YPMEHGIVK & 1 & $+0.3^{c}$ \\
\hline 40S ribosomal protein $\mathrm{S} 19$ & Q8WVX7 & MVEKDQDGGR & 1 & $+0.3^{c}$ \\
\hline T-Complex protein 1 subunit $a$ & P17987 & YFVEAGAMAVR & 12 & $+0.3^{c}+0.3^{e}$ \\
\hline Filamin A & $\mathbf{P 2 1 3 3 3}$ & GAGSYTIMVLFADQATPTSPIR & 2 & $\mathbf{- 0 . 6 ^ { b , d }}$ \\
\hline Plastin-2 & P13796 & GDEEGVPAVVIDMSGLR & 2 & $-0.6^{d}$ \\
\hline Dynein 1 heavy chain 1 & Q14204 & ALPDMEVVGLNFSSATTPELLLK & 2 & $-0.5^{d}$ \\
\hline Vesicle trafficking protein SEC22B & O75396 & VADGLPLAASM(OX)QEDEQSGR & 2 & $+1.0^{d}$ \\
\hline Heterogeneous nuclear ribonucleo-protein $\mathrm{M}$ & P52272 & MGAGLGHGMDR & 2 & $-0.4^{d}$ \\
\hline Trifunctional enzyme subunit $\beta$ & P55084 & DLMPHDLAR & 2 & $-0.3^{d}$ \\
\hline CD44 antigen & P16070 & ESSETPDQFMTADETR & 2 & $-0.3^{c}$ \\
\hline
\end{tabular}

${ }^{a}$ Positive and negative values indicate ligand-induced stabilizations and destabilizations, respectively

${ }^{b}$ Multiple product ion mass spectra were averaged in both (-) and (+) ligand samples.

$c^{c}$ Shift includes one significant iTRAQ reporter ion difference between the transition regions of the (-) and (+) ligand chemical denaturation curves.

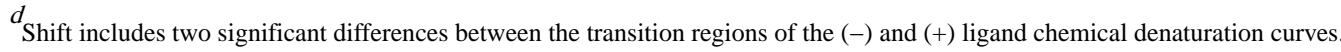

${ }^{e}$ Shift includes three significant differences between the transition regions of the (-) and (+) ligand chemical denaturation curves. 
Table 3

Summary of peptide and protein hits identified in the SILAC-PP experiment. Bolded protein entries were also identified as hits in iTRAQ-SPROX.

\begin{tabular}{|c|c|c|c|c|}
\hline Protein Name & Accession Number & $\begin{array}{c}\text { Gel Row and Molecular Weight } \\
\text { Range (kDa) }\end{array}$ & $\begin{array}{c}\text { Intact Protein Molecular Weight } \\
\text { (kDa) }\end{array}$ & $\Delta \mathrm{C}_{1 / 2}(\mathrm{M})^{a}$ \\
\hline \multirow[t]{2}{*}{ Filamin A } & $\mathbf{P 2 1 3 3 3}$ & $1(>150)$ & 281 & -2.0 \\
\hline & & $2(100-150)$ & 281 & +1.5 \\
\hline \multirow[t]{2}{*}{ Filamin $\mathrm{B}^{b}$} & O75369 & $1(>150)$ & 278 & -1.5 \\
\hline & & $2(100-150)$ & 278 & -2.3 \\
\hline$a \operatorname{actinin} 4^{c}$ & O43707 & $2(100-150)$ & 105 & -1.5 \\
\hline \multicolumn{5}{|l|}{ Heat shock cognate } \\
\hline $71 \mathrm{kDa}$ protein $b, c$ & $\mathrm{P} 11142$ & $4(65-75)$ & 71 & -1.5 \\
\hline Cytochrome P450 2B6 & P20813 & $5(55-65)$ & 56 & -1.6 \\
\hline \multirow[t]{2}{*}{ Elongation factor 1-a } & P68104 & $5(55-65)$ & 50 & +3.0 \\
\hline & & $8(37-43)$ & $\mathbf{5 0}$ & +1.5 \\
\hline \multicolumn{5}{|l|}{ Fructose-bisphosphate } \\
\hline aldolase $\mathrm{C}$ & P09972 & $8(37-43)$ & 39 & +2.0 \\
\hline Actin & P62736 & $9(34-37)$ & 42 & +1.0 \\
\hline \multicolumn{5}{|l|}{ L-lactate } \\
\hline \multirow[t]{2}{*}{ dehydrogenase A } & P00338 & $9(34-37)$ & 37 & -1.3 \\
\hline & P00338 & $10(20-34)$ & 37 & -1.0 \\
\hline
\end{tabular}

${ }^{a}$ Positive and negative values represent hits resulting from positive and negative deviations, respectively, of $\log _{2}(\mathrm{~L} / \mathrm{H})$ values. The positive and negative values for proteins analyzed in molecular weight regions corresponding to the intact protein indicate stabilizations and destabilizations, respectively.

$b_{\text {P }}$ iTRAQ-SPROX experiment.

${ }^{c}$ Protein was identified as a hit based on data from a single peptide. 